\title{
Enhancing Colloidal Quantum Dot Tandem Solar Cell Performance by Graded Band Alignment
}

\author{
Supporting Information
}

Yijun Gao ${ }^{\dagger}$, Jianghui Zheng ${ }^{\dagger}$, Weijian Chen ${ }^{\dagger,+}$, Lin Yuan ${ }^{\dagger,}$, Zhi Li Teh ${ }^{\dagger}$, Xin Cui ${ }^{\dagger}$, Gavin Conibeer $^{\dagger}$, Robert Patterson ${ }^{\dagger}$, Shujuan Huang ${ }^{*},+\|$

$\dagger$ Australian Centre for Advanced Photovoltaics, School of Photovoltaic and Renewable Energy Engineering, University of New South Wales, Sydney 2052, Australia.

$\$$ Centre for Translational Atomaterials, Swinburne University of Technology, Vic 3122, Australia

$\S$ Department of Chemistry-Ångström, Physical Chemistry, Uppsala University, 75120 Uppsala, Sweden

" School of Engineering, Macquarie University, Sydney 2109, Australia

* Corresponding Author:

Email: sj.huang@unsw.edu.au 


\section{EXPERIMENTAL AND MODELLING METHODS}

Modelling method and data acquiring:

Ellipsometer measurements were used to obtain optical constants for the CQD layers. A J.A. Woollam variable angle spectroscopic ellipsometer was used for this measurement. Samples for these measurements consisted of $\mathrm{PbS}$ quantum dots films deposited by spin-coating quantum dot colloids onto silicon wafers having thermally oxidized surfaces. The thicknesses of quantum dot films were estimated from a cross-sectional scanning electrons microscope image. The data acquired were fitted with a WVase software employing Cauchy model.

PVlighthouse Ray-tracer (https://www.pvlighthouse.com.au/sunsolve): The PVlighthouse Sunsolve module, with modifications, was employed to perform optical modelling of the tandem structure. The optical parameters of absorbing layers obtained from the ellipsometer measurement and fitting were used as input data. Optical parameters of other functional layers were acquired from the PVlighthouse database.

Preparation of $\mathrm{PbS}$ quantum dots

$\mathrm{PbS}$ CQDs for front and rear cells were fabricated referring to previously reported methods, with modifications. ${ }^{1-4}$ For the front cell CQDs with a bandgap of $1.44 \mathrm{eV}$, a mixture of Bis(trimethylsilyl)sulfide (TMS, $0.12 \mathrm{~g}$ ) and 1-octadecene (ODE, $4 \mathrm{~g}$ ) was prepared firstly. Then, a mixture of $\mathrm{PbO}(0.45 \mathrm{~g})$, oleic acid $(\mathrm{OA}, 1.5 \mathrm{~g})$ and $\mathrm{ODE}(15 \mathrm{~g})$ was heated to $100^{\circ} \mathrm{C}$ for 3 hours under vacuum. The mixture was then cooled down to $75^{\circ} \mathrm{C}$ followed by injection of the TMS/ODE mixture solution. The resulting colloidal solution was removed from the heating mantel and allowed to cool down naturally. The as-synthesized PbS CQDs were purified by centrifugation using acetone as an anti-solvent and hexane as a solvent for three times. The final quantum dots were dispersed in hexane at a concentration of $20 \mathrm{mg} / \mathrm{ml}$. 
For synthesizing rear cell CQD, a similar process was used with different amount of oleic acid and reaction temperature to produce different sizes. For the absorbing QDs with a bandgap of $1.22 \mathrm{eV}$, the amount of oleic acid was doubled and the injection performed at $95^{\circ} \mathrm{C}$. For CQDs with a bandgap of $1.13 \mathrm{eV}$, the amount of oleic acid was quadrupled and injection at $95^{\circ} \mathrm{C}$ was performed. All chemicals were purchased from Sigma-Aldrich and used as received.

Preparation of $\mathrm{ZnO}$ nanoparticles

$\mathrm{ZnO}$ nanoparticles (NPs) were synthesized following a previously reported method. ${ }^{3,5-7} \mathrm{~A}$ solution of potassium hydroxide $(2.95 \mathrm{~g})$ in methanol $(125 \mathrm{ml})$ was added to a solution of zinc acetate dehydrate $(1.48 \mathrm{~g})$ in methanol $(65 \mathrm{ml})$ slowly at $60^{\circ} \mathrm{C}$. Then, the solution was stirred at $60^{\circ} \mathrm{C}$ for $2 \mathrm{~h} . \mathrm{ZnO}$ nanoparticles were extracted by centrifugation and washed using methanol twice. Chloroform and methanol were mixed in a $1: 1$ (vol) ratio as the final solvent in which the $\mathrm{ZnO}$ nanoparticles were dissolved. For the interlayer $\mathrm{ZnO}-\mathrm{NP}, 1$-butanol was used instead of methanol as final solvent. The $\mathrm{ZnO}$ doping process was performed based on a previously reported method. ${ }^{8} \mathrm{~A} 1 \mathrm{ml} \mathrm{MgCl} 2$ solution having a concentration of $0.7 \mathrm{mmol} / \mathrm{ml}$ in methanol was added drop-wise into $30 \mathrm{ml}$ of the as-synthesized $\mathrm{ZnO}$ nanoparticle solution making the mole ratio of $\mathrm{Mg}: \mathrm{Zn}=1: 50$. The mixed solution was stored at room temperature for more than 5 hours before being used.

Fabrication of $\mathrm{PbS}$ single-junction and tandem solar cells

The ITO glass substrate was cleaned using detergent, distilled water, IPA (isopropyl alcohol) and acetone respectively, followed by UV-Ozone cleaning for $10 \mathrm{~min}$. The previously synthesized $\mathrm{ZnO}-\mathrm{NP}$ solution was spin coated onto the clean ITO glass at $2500 \mathrm{rpm}$ for $30 \mathrm{~s}$. This process was repeated twice and the samples were kept at room temperature for an hour to completely dry the solvent. Then, the PbS-OA CQD solution was spin coated at $3000 \mathrm{rpm}$ 
for 30s. After soaking the spin-coated $\mathrm{PbS}-\mathrm{OA}$ film in $\mathrm{PbI}_{2}$ solution (4.6 $\mathrm{mg} / \mathrm{ml}$ in $\mathrm{DMF}$ ) for 45s, a layer of PbS QDs treated with $\mathrm{PbI}_{2}$ (PbS-I) was obtained for light absorbing layer. This layer was then rinsed with acetonitrile $(\mathrm{ACN})$. This $\mathrm{PbS}-\mathrm{I}$ layer fabrication process was repeated multiple times to reach a desired thickness. For the deposition of the hole transporting layer, ethanedithiol (EDT) was used for ligand exchange to form a PbS-EDT layer. Two layers of PbS-EDT were deposited on the PbS-I layer using EDT $(0.015 \%$ vol in $\mathrm{ACN}$ ) to treat the PbS-OA QD layer, which was finally washed with ACN. Approximately $100 \mathrm{~nm}$ of Au was evaporated onto the final CQD film as an electrode.

For the graded rear cell structure fabrication, just replace the CQD in the first layer in PbS-I $(1.22 \mathrm{eV})$ layers with $1.13 \mathrm{eV}$ CQDs and that in the last layer with $1.44 \mathrm{eV}$ CQDs. As well, CQDs for PbS-EDT layers were replaced by $1.44 \mathrm{eV}$ CQDs for forming the graded cell structure. The total numbers of deposited layers for graded and non-graded cells were kept the same in both PbS-I and PbS-EDT absorbing layers.

To fabricate tandem cells, first the front cell was fabricated following the single-junction cell process using large bandgap $(1.44 \mathrm{eV})$ quantum dots. Then, an Au layer with a thickness of 2 $\mathrm{nm}$ was evaporated onto the front cell. The evaporation was conducted at a rate of $0.1 \AA / \mathrm{s}$ under $1 \times 10^{-6}$ mTorr. A thickness meter could monitor the real-time thickness of the deposited Au film. A ZnO-NP layer with or without surface doping was then spin-coated on top of the $\mathrm{Au}$ interlayer at $2500 \mathrm{rpm}$ for 30s. Then, the remaining rear cell was fabricated following the single-junction cell process with narrow band gap quantum dots with and without graded band alignment.

Material and device characterization:

The absorption spectra were measured on a Perkin Elmer Lambda1050 UV/Vis/NIR spectrophotometer. 
Ultraviolet photoelectron spectroscopy (UPS) was performed using an ESCALAB250Xi system produced by Thermo Scientific (UK). The ultraviolet source was a He Iamp (energy $21.2 \mathrm{eV})$

Scanning electron microscope (SEM) images were obtained using an FEI Nova Nano 450 SEM.

The current density-voltage $(\mathrm{J}-\mathrm{V})$ measurements were performed using an IV5 solar cell J-V testing system from PV measurements, Inc. with a Keithley 2400 source meter and an AM1.5G Oriel model 94023A solar simulator. The incident illumination power is 1000 $\mathrm{W} / \mathrm{m}^{2}$. A forward scan was used from $-0.25 \mathrm{~V}$ to $0.75 \mathrm{~V}$. The cell area was $0.03 \mathrm{~cm}^{2}$.

The external quantum efficiency (EQE) measurement was performed on a PV Measurement QXE7 spectral response system with monochromatic light generated by a xenon arc lamp. The EQE of the rear cell was measured by placing a single-junction front cell as a filter in front of a single-junction rear cell. This measurement method was proven to be acceptable by reported researches. ${ }^{9-11}$

All characterizations were performed at room temperature in ambient conditions except the UPS and SEM that were carried out in a vacuum chamber. 


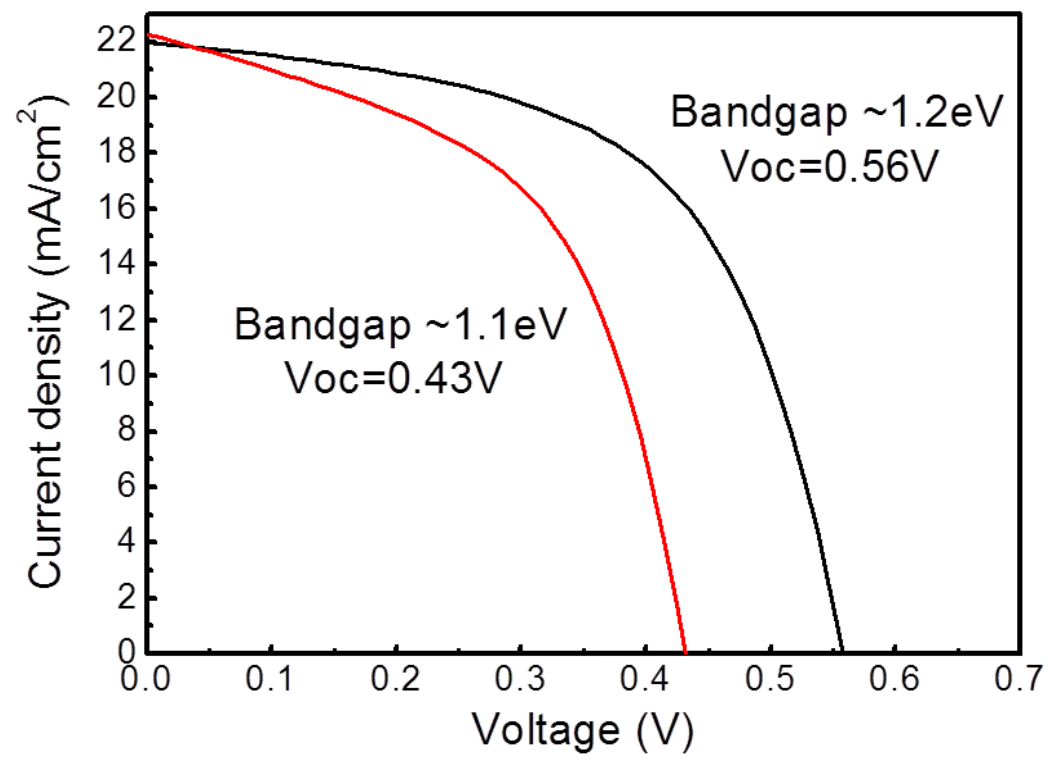

Figure $\mathrm{S} 1 \mathrm{~J}-\mathrm{V}$ curves of single-junction PbS CQD solar cells with bandgaps of $1.2 \mathrm{eV}$ and 1.1 eV.

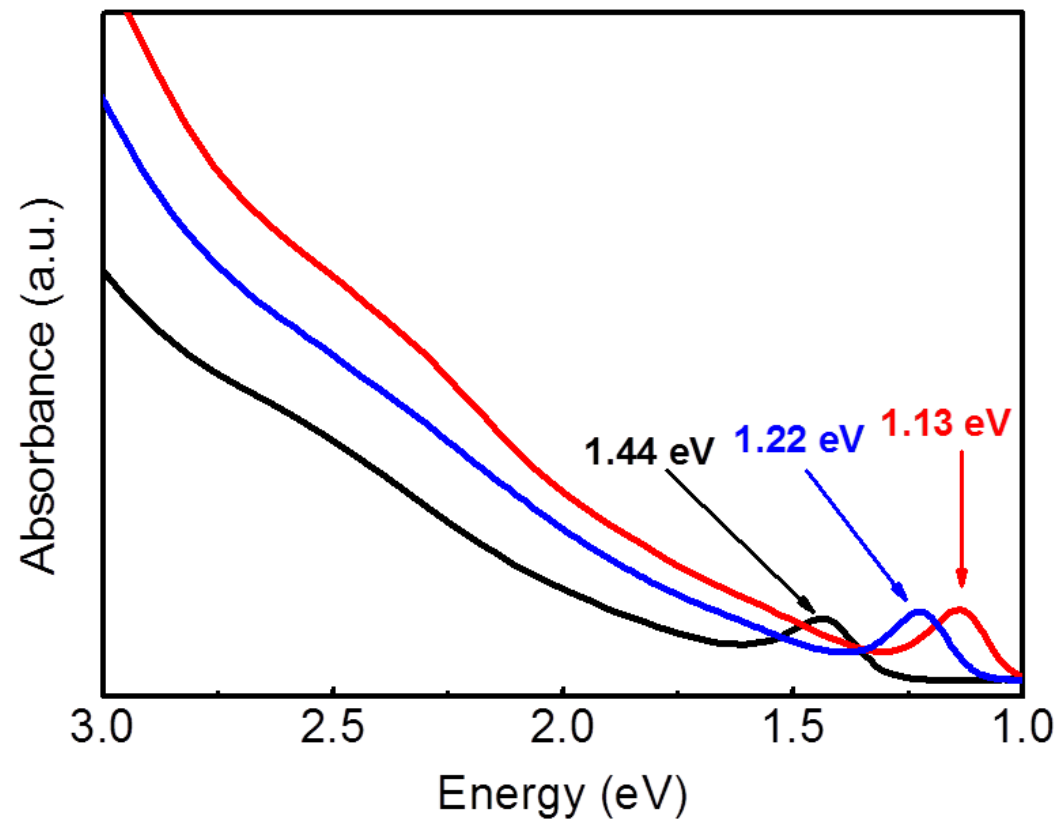

Figure S2 Absorbance of quantum dots synthesised with different bandgaps that were used in this research. 


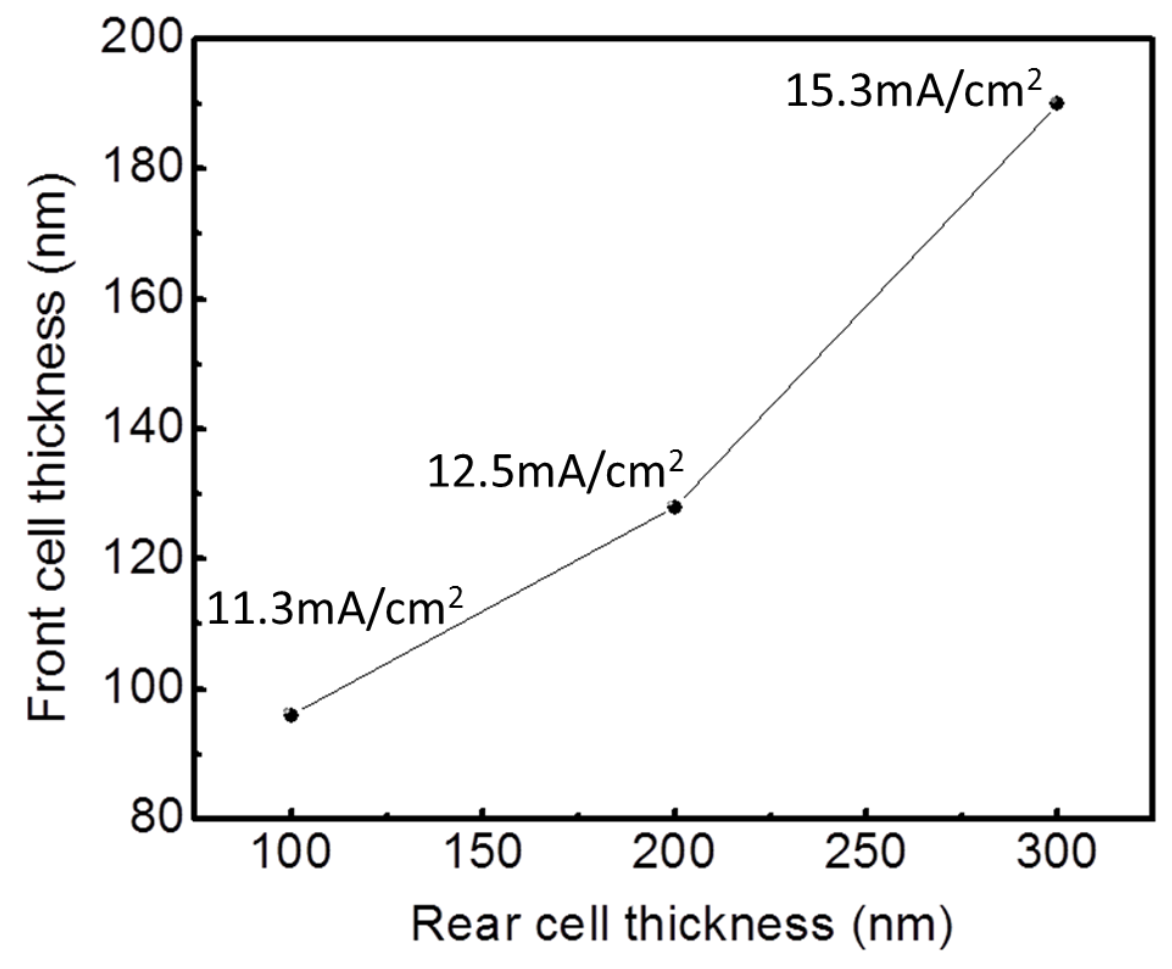

Figure S3 Relationship between front and rear cell thicknesses and matched tandem cell current densities based on results from the optical model. 
(a)

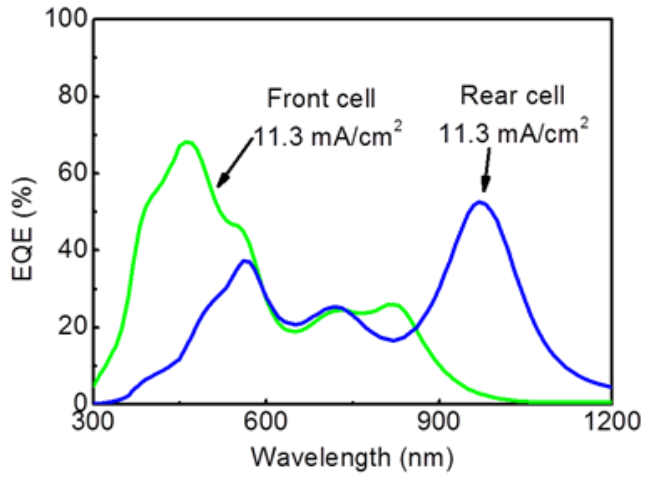

a

(c)

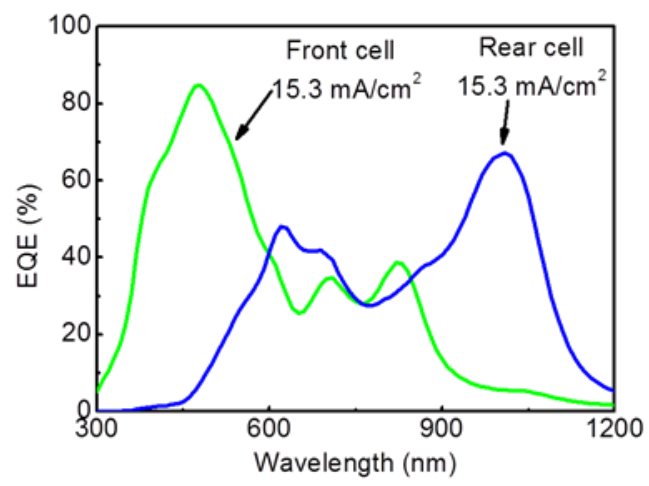

C (b)

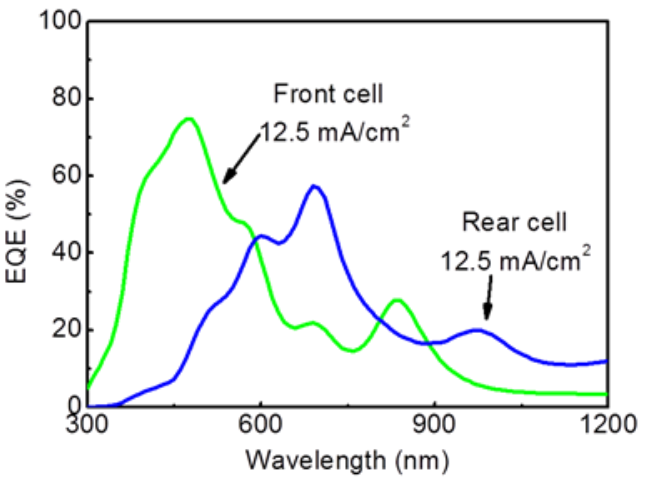

b

(d)

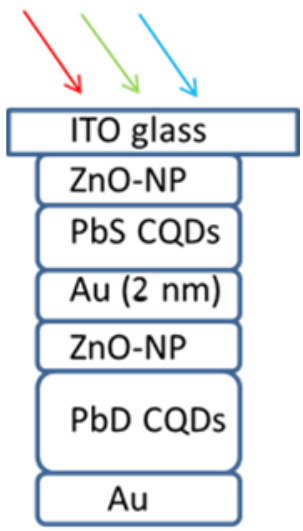

d

Figure S4 Modelled EQEs for the front and rear cells with rear cell absorbing layer thicknesses of (a) $100 \mathrm{~nm}$, (b) $200 \mathrm{~nm}$, (c) $300 \mathrm{~nm}$. (d) Illustration of the modelled tandem structure.

Table S1 Parameters of the modelled tandem cells with different rear cell thicknesses

\begin{tabular}{c|c|c|c}
\hline \hline Au thickness & $\begin{array}{c}\text { Front cell } \\
\text { thickness }\end{array}$ & $\begin{array}{c}\text { Rear cell } \\
\text { thickness }\end{array}$ & $\begin{array}{c}\text { Matched } \\
\text { Current }\end{array}$ \\
\hline $2 \mathrm{~nm}$ & $96 \mathrm{~nm}$ & $100 \mathrm{~nm}$ & $11.3 \mathrm{~mA} / \mathrm{cm}^{2}$ \\
\hline $2 \mathrm{~nm}$ & $128 \mathrm{~nm}$ & $200 \mathrm{~nm}$ & $12.5 \mathrm{~mA} / \mathrm{cm}^{2}$ \\
\hline $2 \mathrm{~nm}$ & $190 \mathrm{~nm}$ & $300 \mathrm{~nm}$ & $15.3 \mathrm{~mA} / \mathrm{cm}^{2}$ \\
\hline \hline
\end{tabular}




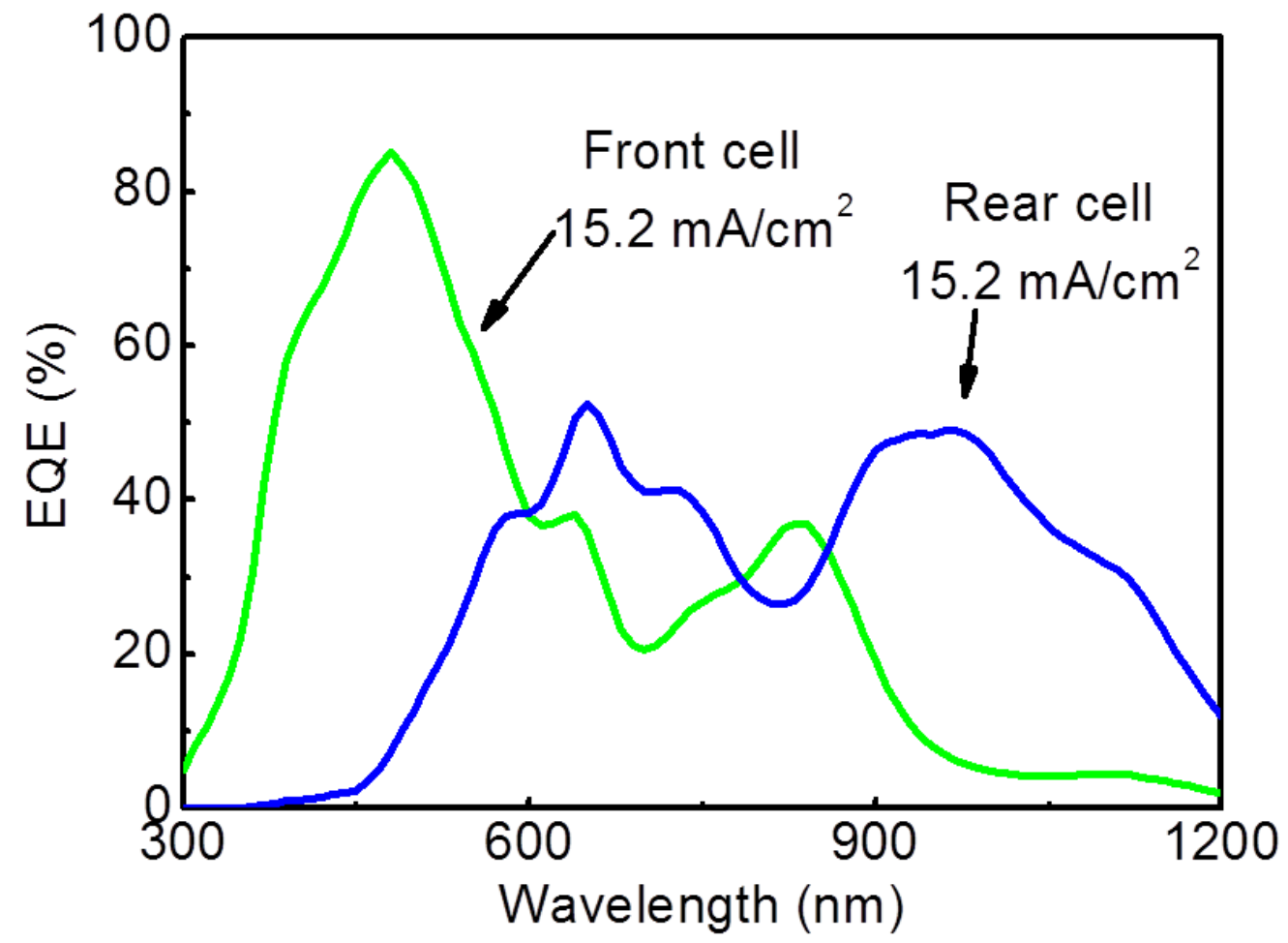

Figure S5 Simulated EQEs of tandem solar cell with an ITO interlayer. The simulated front and rear cell thicknesses are $190 \mathrm{~nm}$ and $300 \mathrm{~nm}$. Applying a $60 \mathrm{~nm}$ ITO interlayer to replace the $\mathrm{Au}$ interlayer could eliminate the peak at $700 \mathrm{~nm}$ for the front cell as shown in Figure $1 \mathrm{~b}$. 


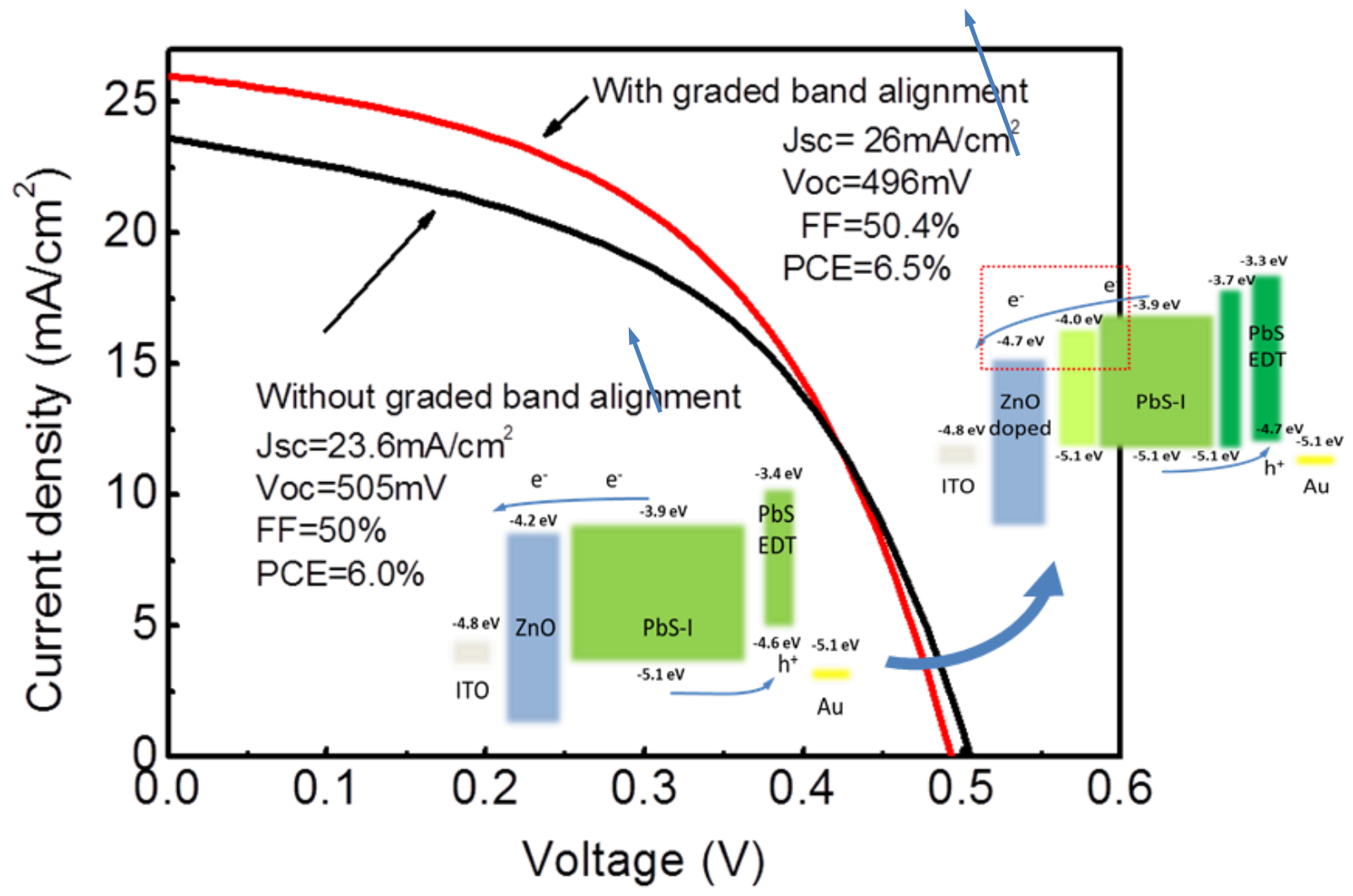

Figure S6 J-V curves of single-junction PbS CQD solar cells with and without graded band alignment. The graded band alignment increases the PCE of single-junction cells mainly due to increased current density. CQDs for the absorbing layer in these two single-junction cells have the same bandgap of $1.22 \mathrm{eV}$. 

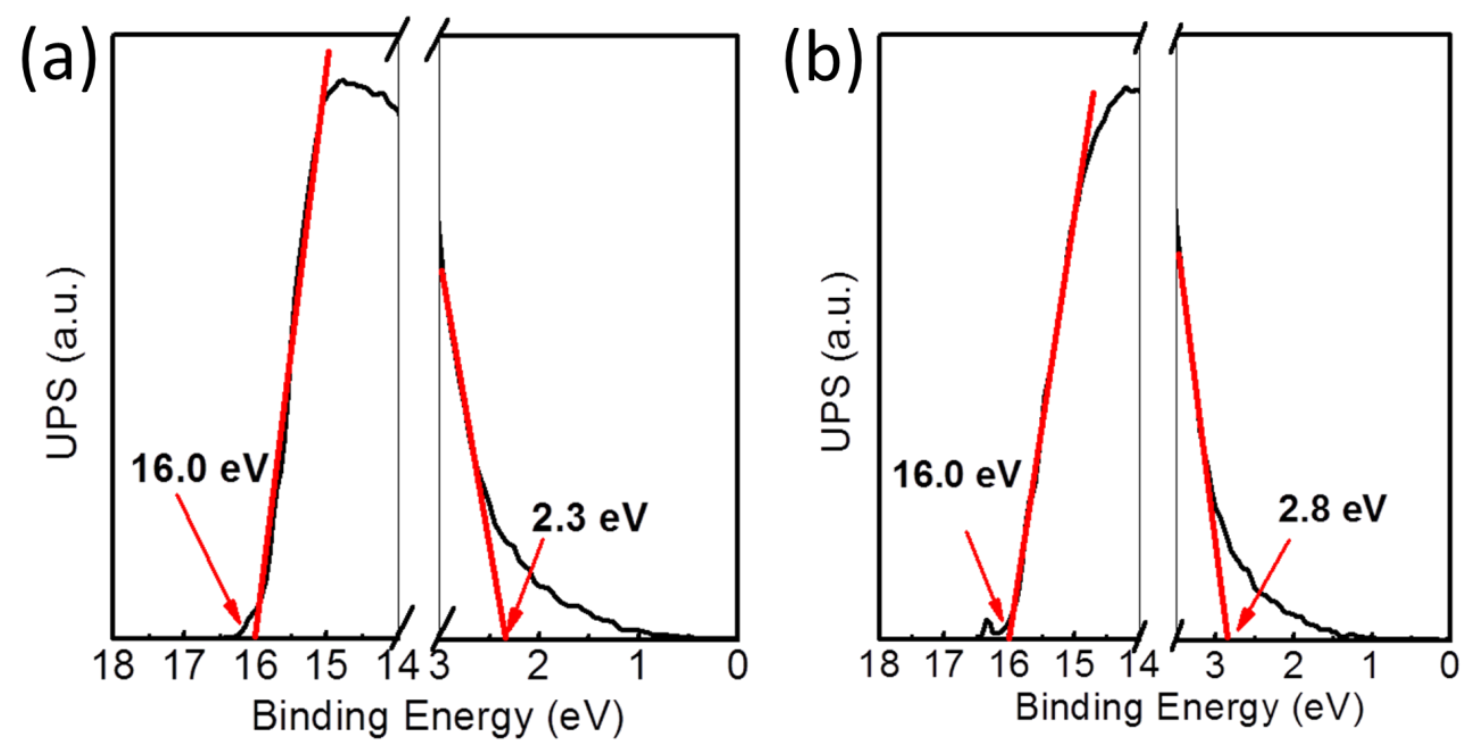

Figure S7 UPS of ZnO nanocrystals before (a) and after (b) applying surface doping. By applying surface doping, the $\mathrm{ZnO}$ nanocrystals' conduction band was observed to shift from $-4.2 \mathrm{eV}$ to $-4.7 \mathrm{eV}$.

Table S2 Band energy levels of CQDs with different sizes. ${ }^{12-14}$

\begin{tabular}{|c|c|c|c|c|c|}
\hline & $5.1 \mathrm{~nm}$ PbS-I & $4.3 \mathrm{~nm}$ PbS-I & $3.6 \mathrm{~nm}$ PbS-I & $4.3 \mathrm{~nm}$ PbS-EDT & $3.6 \mathrm{~nm}$ PbS-EDT \\
\hline Conduction band & $-4.0 \mathrm{eV}$ & $-3.9 \mathrm{eV}$ & $-3.7 \mathrm{eV}$ & -3.4 & $-3.3 \mathrm{eV}$ \\
\hline Valance band & $-5.1 \mathrm{eV}$ & $-5.1 \mathrm{eV}$ & $-5.1 \mathrm{eV}$ & -4.6 & $-4.7 \mathrm{eV}$ \\
\hline
\end{tabular}




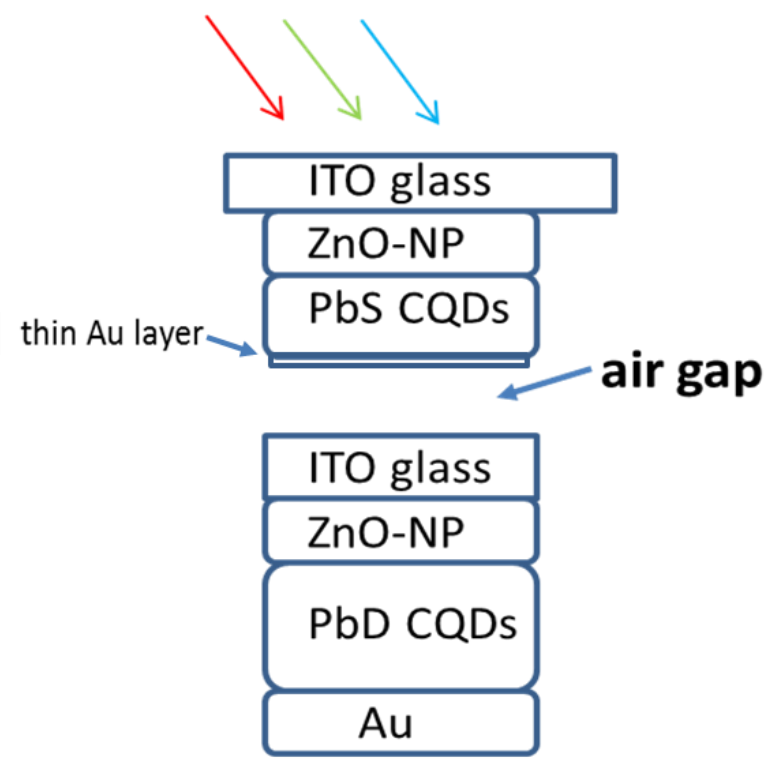

Figure S8 A Schematic diagram for EQE measurement of the rear cell using a single-junction front cell as a filter. This configuration introduces an air-gap in between the sub-cells and additional ITO glass absorption compared with the monolithic tandem structure in Figure $1 \mathrm{a}$. The air-gap causes light scattering and additional interfaces, so that there would be additional light loss and current drop in the measured EQE of the rear cell. The additional ITO glass's absorption may also reduce current.

(1) Zhang, X.; Hägglund, C.; Johansson, E. M. J. Highly Efficient, Transparent and Stable Semitransparent Colloidal Quantum Dot Solar Cells: a Combined Numerical Modeling and Experimental Approach. Energy Environ. Sci. 2017, 10, 216-224.

(2) Zhang, X.; Johansson, E. M. Reduction of Charge Recombination in PbS Colloidal Quantum Dot Solar Cells at The Quantum Dot/ZnO Interface by Inserting a MgZnO Buffer Layer. J. Mater. Chem. A 2017, 5, 303-310.

(3) Chuang, C. H. M.; Brown, P. R.; Bulović, V.; Bawendi, M. G. Improved Performance and Stability in Quantum Dot Solar Cells through Band Alignment Engineering. Nat. Mater. 2014, 13, 796-801.

(4) Lu, K.; Wang, Y.; Liu, Z.; Han, L.; Shi, G.; Fang, H.; Chen, J.; Ye, X.; Chen, S.; Yang, F. High Efficiency PbS Quantum - Dot Solar Cells with Greatly Simplified Fabrication Processing via "Solvent - Curing". Adv. Mater. 2018, 30, 1707572.

(5) Choi, J.; Kim, Y.; Jo, J. W.; Kim, J.; Sun, B.; Walters, G.; Garcia de Arquer, F. P.; Quintero-Bermudez, R.; Li, Y.; Tan, C. S., et al. Chloride Passivation of ZnO Electrodes Improves Charge Extraction in Colloidal Quantum Dot Photovoltaics. Adv. Mater. 2017, 29, 1702350.

(6) Beek, W. J. E.; Wienk, M. M.; Kemerink, M.; Yang, X.; Janssen, R. A. J. Hybrid Zinc Oxide Conjugated Polymer Bulk Heterojunction Solar Cells. J. Phys. Chem. B 2005, 109, 9505-9516.

(7) Liu, M.; Voznyy, O.; Sabatini, R.; García de Arquer, F. P.; Munir, R.; Balawi, Ahmed H.; Lan, X.; Fan, F.; Walters, G.; Kirmani, Ahmad R., et al. Hybrid Organic-inorganic Inks Flatten the Energy Landscape in Colloidal Quantum Dot Solids. Nat. Mater. 2017, 16, 258-263. 
(8) Gao, Y.; Patterson, R.; Hu, L.; Yuan, L.; Zhang, Z.; Hu, Y.; Chen, Z.; Teh, Z. L.; Conibeer, G.; Huang, S. $\mathrm{MgCl}_{2}$ Passivated ZnO Electron Transporting Layer to Improve PbS Quantum Dot Solar Cells. Nanotechnology 2018, 30, 085403.

(9) Shi, G.; Wang, Y.; Liu, Z.; Han, L.; Liu, J.; Wang, Y.; Lu, K.; Chen, S.; Ling, X.; Li, Y., et al. Stable and Highly Efficient PbS Quantum Dot Tandem Solar Cells Employing a Rationally Designed Recombination Layer. Adv. Energy Mater. 2017, 1602667.

(10) Zhang, Y.; Gu, M.; Li, N.; Xu, Y.; Ling, X.; Wang, Y.; Zhou, S.; Li, F.; Yang, F.; Ji, K., et al. Realizing Solution-processed Monolithic PbS QDs/perovskite Tandem Solar Cells with High UV Stability. J. Mater. Chem. A 2018, 6, 24693-24701.

(11) Timmreck, R.; Meyer, T.; Gilot, J.; Seifert, H.; Mueller, T.; Furlan, A.; Wienk, M. M.; Wynands, D.; Hohl-Ebinger, J.; Warta, W. Characterization of Tandem Organic Solar Cells. Nat. Photonics 2015, 9, 478-479.

(12) Hou, B.; Cho, Y.; Kim, B. S.; Hong, J.; Park, J. B.; Ahn, S. J.; Sohn, J. I.; Cha, S.; Kim, J. M. Highly Monodispersed PbS Quantum Dots for Outstanding Cascaded-Junction Solar Cells. ACS Energy Lett. 2016, 1, 834-839.

(13) Yeon, D. H.; Lee, S. M.; Jo, Y. H.; Moon, J.; Cho, Y. S. Origin of the Enhanced Photovoltaic Characteristics of PbS Thin Film Solar Cells Processed at Near Room Temperature. J. Mater. Chem. A 2014, 2, 20112-20117.

(14) Brown, P. R.; Kim, D.; Lunt, R. R.; Zhao, N.; Bawendi, M. G.; Grossman, J. C.; Bulović, V. Energy Level Modification in Lead Sulfide Quantum Dot Thin Films through Ligand Exchange. ACS nano 2014, 8, 5863-5872. 